\title{
Effect of Light and Irrigation on the Growth of Vigna radiata (Mung Bean) Microgreens
}

\author{
Shivaani Manickavasagan \\ Guelph Collegiate Vocational Institute, 155 Paisley Street, Guelph, Ontario, N1H 2P3, Canada ;shivaanimanick@gmail.com
}

ABSTRACT: There is an increasing demand for microgreens (ten-day old baby plants) globally due to their taste and nutritional values. In this study, the feasibility of growing Vigna radiata microgreens at home, and the effect of light (growth light [LED] vs room light [Fluorescence] and irrigation water [10, 20,30,40,50, $60 \mathrm{~mL} /$ day] on shoot count and hypocotyl length were determined. The experiment was conducted in plastic trays filled with soil $(4 \mathrm{~cm}$-depth). The results suggested that it was feasible to grow Vigna radiata microgreens at home under both light conditions with acceptable sensory qualities. The growth (sprouting, cotyledon development and readiness-to-harvest) was faster under the growth light condition than that of room light. However, the hypocotyl length was greater under room light than growth light. The microgreens grown under growth light were darker in color and harder in texture than room light. The hypocotyl length was significantly longer for the $60 \mathrm{~mL} /$ day treatment, followed by $10 \mathrm{~mL} /$ day treatment, and with no differences between other irrigation levels. Based on the observation of denser root systems at the bottom surface of the tray under growth light conditions, there might be insufficient soil for root development. Further research is warranted to determine the nutritional qualities of Vigna radiata microgreens in plots with greater soil depths.

KEYWORDS: Botany; Mung bean; Microgreens; Irrigation; LED light; Fluorescent light.

\section{- Introduction}

Microgreens are a relatively new concept that started in the early 1980s. Microgreens are seven to ten days old small plants, harvested with two cotyledons. There has been a recent increase in the consumption of microgreen as specialty vegetables due to their taste and high content of functional components such as minerals, phenolics, vitamins, and antioxidants. ${ }^{1}$ They are being consumed in fresh salads, soups, and other dishes. The nutritional qualities and bioactive components present in microgreens are higher than that of mature greens. Regular consumption of microgreens reduces the risk factors for obesity, cardiovascular diseases, Type 2 diabetes and certain types of cancer. ${ }^{2}$

In the official list of the American Microgreen Industries, there are 25 types of microgreens such as, Brassica oleracea $L$. var. italica (broccoli), Eruca sativa Mill (arugula), Brassica rapa L. var. ruvo (turnip), that are available commercially. ${ }^{2}$ However, $V$. radiata is not available in that list. Furthermore, there is no published work available about this type of microgreen in the public domain.

Vigna radiata, popularly known as green gram or mung bean, believed to be a native crop of India, is a small green spherical shaped bean. V. radiata is an important legume crop in Asia, where it compliments cereal-based diets with a large proportion of digestible protein through use as a pulse. In many developing and developed countries, mung bean is used in the sprouted form. ${ }^{3}$

Since the total time required to grow microgreens is only seven to ten days, people are showing interest in growing them at home for consumption. Therefore, the optimum growth condition is required for the maximum yield of microgreens. The growing conditions have significant effects on the yield and nutritional qualities of microgreens. Light influences the production of secondary metabolites in plants. ${ }^{2}$ Several researchers have investigated the effect of different lights on the nutritional qualities of microgreens. ${ }^{4-7}$ Vastakaite et al. investigated the effect of pulsed LED during the cultivation of Brassica rapa (red bak choi), Brassica juncea (mustard) and Brassica rapa (tatsoi) on the phytochemical contents. ${ }^{7}$ It was determined that the phytochemical composition of microgreens was significantly affected by pulsed LED. Samuoliene et al. obtained 1.2 to 4.3 times higher concentration of chlorophylls and carotenoids in Brassica juncea L. (mustard), Beta vulgaris L (beet), and Petroselinum crispum mill (parsley) microgreens under blue LED light. ${ }^{4}$

If the optimum growth condition is established for $V$. radiata microgreens, then it will be beneficial for the home growers. Therefore, the objective of this study was to determine the effect of light and irrigation on the number of shoots and hypocotyl length of $V$. radiata microgreens. Two types of light (growth light (LED) and room light (fluorescent)) and six levels of irrigations $(10 \mathrm{~mL}, 20 \mathrm{~mL}, 30 \mathrm{~mL}, 40 \mathrm{~mL}, 50 \mathrm{~mL}$ and $60 \mathrm{~mL}$ per day) were used in this study. The experimental set up is shown in Figures 1-3.

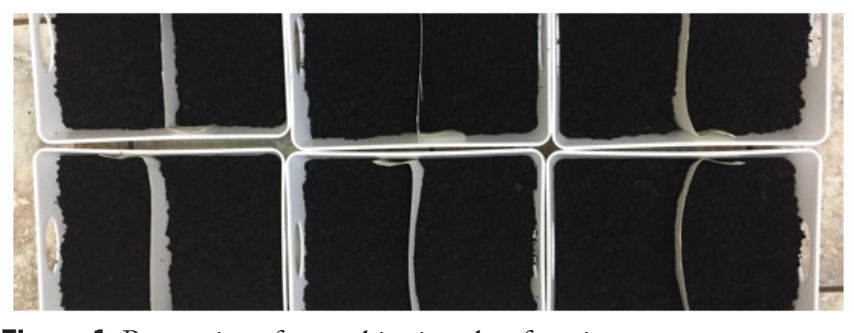

Figure 1: Preparation of tray cultivation-plots for microgreens. 


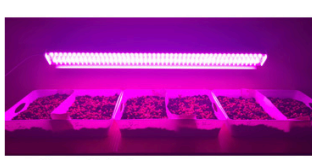

Growth light

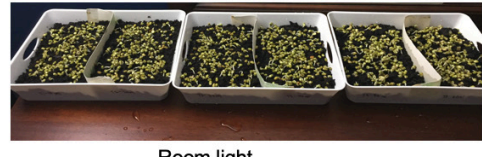

Room light
Figure 2: Experimental setup for microgreen growth.

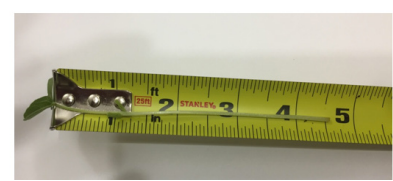

Figure 3: Measuring length of hypocotyl.

\section{- Results and Discussion}

The growth light showed an accelerated growth in microgreens compared to the room light. This difference was first observed on Day 2. Sprouts were noticed among the trial plots under growth lights on the second day, whereas it took four days for the room light trials. On the 6th day, many cotyledons also emerged under the growth light (Figure 4).

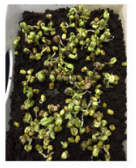

$10 \mathrm{ml} / \mathrm{day}$

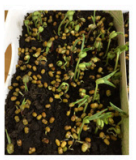

$10 \mathrm{ml} / \mathrm{day}$

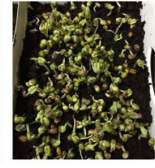

$20 \mathrm{~m} /$ day

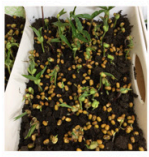

$20 \mathrm{ml} / \mathrm{day}$

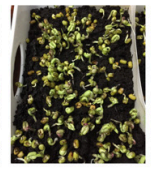

$30 \mathrm{~m} / \mathrm{day}$

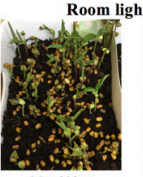

$30 \mathrm{ml} /$ day

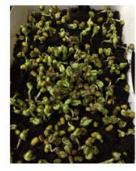

$40 \mathrm{~m} / \mathrm{day}$

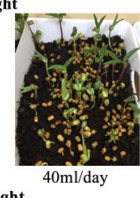

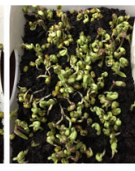

$50 \mathrm{~m} / \mathrm{day}$

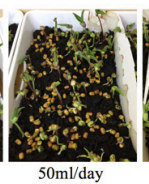

$50 \mathrm{ml} / \mathrm{day}$

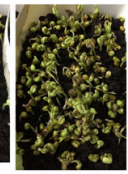

$60 \mathrm{~m} / \mathrm{day}$

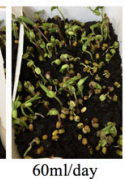

Figure 4: $V$. radiata cultivation plot on sixth day

\section{Harvesting:}

In general, microgreens are harvested after the cotyledons are fully emerged. The seedlings should not be allowed to grow for a prolonged time as bioactive and other nutritional compounds will then be utilized for regular plant growth. In most microgreens, the growth pattern of seedlings is not uniform, therefore it may not possible to harvest them at one time. While waiting for junior microgreens, the senior microgreens might enter the regular plant phase growth (no longer microgreens). Therefore, harvesting in two stages is very common in microgreens. ${ }^{1}$

\section{First harvest:}

Microgreens under the growth light were ready for their first harvest on the $8^{\text {th }}$ day. However, the microgreens under the room light took 11 days to become ready for the harvest. The microgreens were harvested $1 \mathrm{~mm}$ above the soil level. The number of shoots coming from each irrigation plot was counted, and the hypocotyl length was measured immediately. Then, the microgreens were packed in zip-lock bags and stored in a refrigerator as the shelf life of microgreens is only seven to ten days..$^{5}$ After the first harvest, the hypocotyl lengths of the remaining microgreens were short in the growth light treatments compared to the room light treatments (Figure 5). The microgreens harvested under the growth light were dark green and had a firm texture. Whereas, the microgreens were light green and had a succulent texture in the room light treatment (Figure 6).

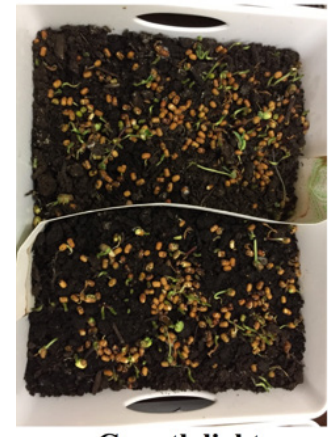

Growth light

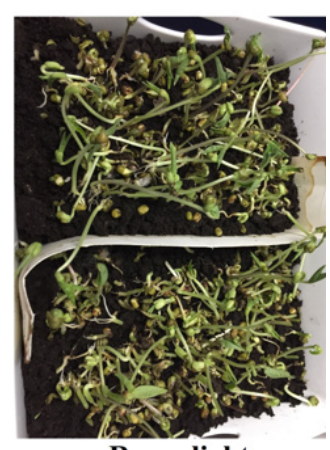

Room light
Figure 5: Cultivation plots after first harvest.

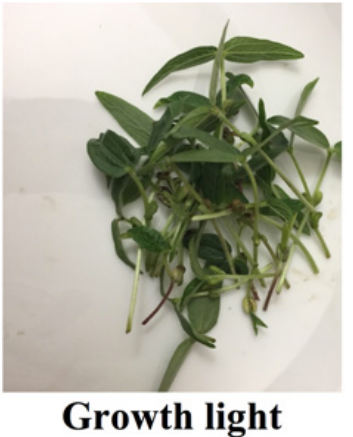

Figure 6: Harvested microgreens.

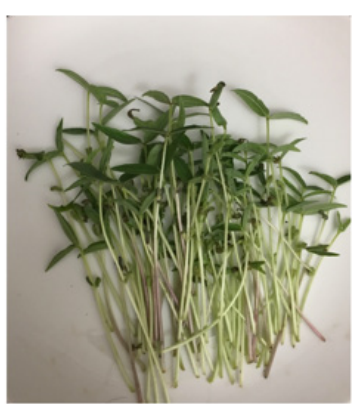

Room light

\section{First}

\section{Second harvest:}

The second harvest was carried out on the $11^{\text {th }}$ day for the growth light treatment and $15^{\text {th }}$ day for the room light treatment. After two harvests, the root systems were analyzed. A more extensive root system was observed in the microgreen plots grown under the growth light than the room light (Figure 7). Furthermore, the roots reached the surface of the tray and accumulated there due to lack of soil in the growth light treatments. The accelerated growth in the growth light treatment produced a more extensive root system, and thus there was no soil for further root penetration. This might have affected the hypocotyl growth. Further work under growth light with deep soil plots might yield different results than that of this study. There was no visual difference in root system between the irrigation treatments under each light.

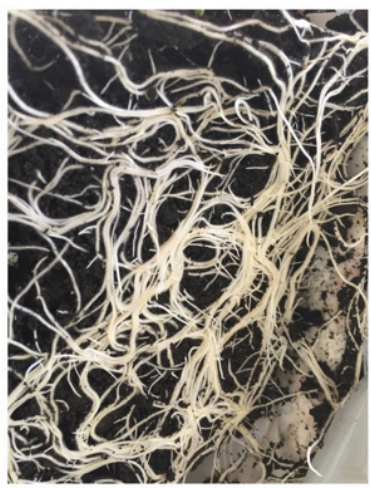

Growth light

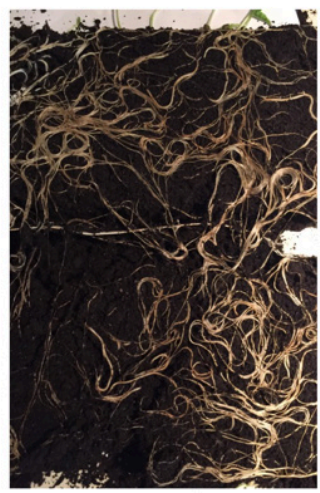

Room light
Figure 7: Root system of microgreens. 


\section{Number of shoots:}

The number of shoots harvested in each treatment is shown in Table 1. Although the room light took 3 extra days for the first harvest, the number of shoots was higher (78 to 139 across irrigation levels) in comparison to the growth light (31 to 63 across irrigation levels). This trend was reversed for the second harvest. The number of shoots were 11 to 16 and 17 to 33 across irrigation levels for the room and growth light treatments, respectively during the second harvest.

Table 1: Total number of shoots.

\begin{tabular}{llllllll}
\hline Light & & \multicolumn{7}{c}{ Irrigation water (mL/ day) } \\
& & 10 & 20 & 30 & 40 & 50 & 60 \\
\hline LED light & First harvest & 31 & 38 & 46 & 44 & 44 & 63 \\
& $\begin{array}{l}\text { Second } \\
\text { harvest }\end{array}$ & 24 & 22 & 24 & 17 & 33 & 30 \\
& Total & $\mathbf{5 5}$ & $\mathbf{6 0}$ & $\mathbf{7 0}$ & $\mathbf{6 1}$ & $\mathbf{7 7}$ & $\mathbf{9 3}$ \\
\hline $\begin{array}{l}\text { Fluorescent } \\
\text { light }\end{array}$ & First harvest & 78 & 103 & 100 & 112 & 139 & 106 \\
& $\begin{array}{l}\text { Second } \\
\text { harvest }\end{array}$ & 13 & 13 & 11 & 16 & 11 & 16 \\
& Total & $\mathbf{9 1}$ & $\mathbf{1 1 6}$ & $\mathbf{1 1 1}$ & $\mathbf{1 2 8}$ & $\mathbf{1 5 0}$ & $\mathbf{1 2 2}$ \\
\hline
\end{tabular}

Figure 8 displays the total number of shoots harvested (harvests 1 and 2) from each irrigation plot under growth light and room light treatments. The $\mathrm{R}^{2}$ value was 0.8 for growth light and 0.6 for room light. Since the outcome of this parameter was "count", a chi-square test (two-way analysis) was conducted. There was no significant difference on the shoot count because of the overall treatments $(p=0.14)$.

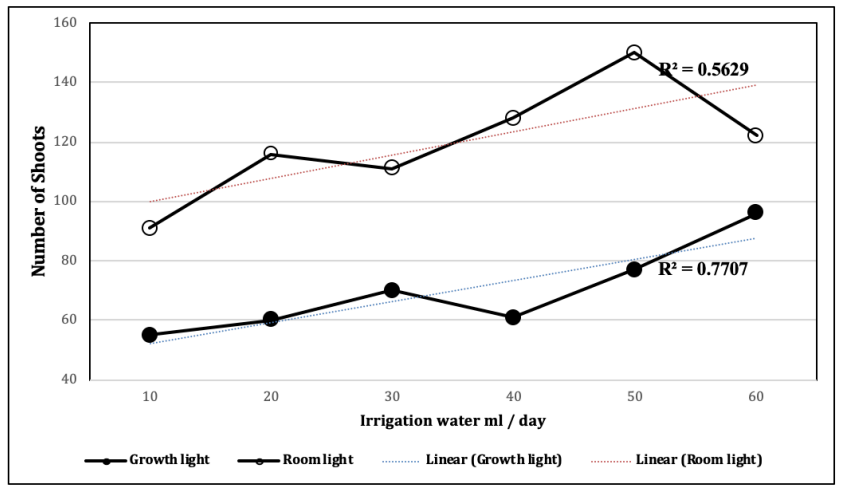

Figure 8: Total number of shoots.

\section{Hypocotyl length:}

Figure 9 shows the mean hypocotyl length (average of harvests 1 and 2) under various irrigation treatments of growth and room light. The $\mathrm{R}^{2}$ value was low in both lights (growth light $=0.208$ and room light $=0.004$ ) compared to that of the shoot count. As two independent variables (light and irrigation) were used in this study, a two-way ANOVA was carried out for the data.

Both light and irrigation level had their own individual effect on the hypocotyl length of Vigna radiata. There was also a significant interaction between the selected independent variables (light type X irrigation level) on the hypocotyl length. The means of hypocotyl length of Vigna radiata microgreens were statistically analyzed using the least significant difference (LSD) method of comparison. The hypocotyl length of Vigna radiata microgreens was significantly higher for the room light than the growth light. Perhaps the room light was insufficient, and the plants were extending to obtain more light. Furthermore, the hypocotyl was significantly longer for available on the effect of irrigation, hypocotyl length or shoot count of microgreens. ${ }^{4-6}$

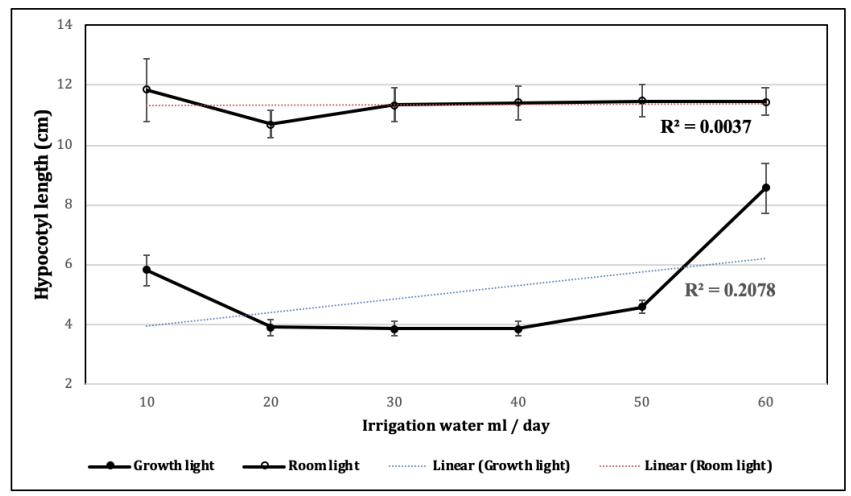

Figure 9: Hypocotyl length.

\section{Conclusion}

Vigna radiata microgreens were successfully grown at home. The growth light accelerated the growth of microgreens as observed from early sprouting, early cotyledon development, and harvest dates compared to the room light. However, the hypocotyl length of the microgreens was shorter in the growth light than that of room light treatment. As an intensive root system was observed near the tray's surface in the growth light treatment, the growth might have been affected due to lack of soil for penetration. Both tested independent variables (light type and irrigation level) had significant effects on the hypocotyl length of the microgreens. A sensory evaluation determined that microgreens grown under growth and room lights were different in texture and appearance. A darker color and firmer texture was noticed from the growth light treated microgreens, and those harvested from the room light were a lighter color and had a succulent texture.

\section{Future work:}

Further work is warranted to determine the growth of Vigna radiata microgreens under growth light without any soil depth limitation, including the dry weight of the plant. Studies for the effect of root development on texture, color and taste of the microgreen would be beneficial for optimizing light and irrigation levels. A detailed sensory evaluation will yield an approximation of consumers' preference for microgreens grown at home. Based on the consumer's preference and nutritional qualities, growth conditions such as light type, irrigation quantity and soil depth could be optimized. Since microgreens are relatively easy to grow at home and rich in nutrition, people should be encouraged to grow and consume Vigna radiata microgreens in their homes.

\section{- Methods \\ Lights:}

LED light (Byingo (2ft, 32W) plant growth light-Full spectrum for indoor plants) was purchased through Amazon. ca. and used in this study. Experiments were conducted in two separate rooms, one with uninterrupted LED lights and the other with uninterrupted fluorescent lights. They were the only lights available in these rooms, which were kept closed all times during the experiments to avoid light interaction from other rooms. 


\section{Room temperature:}

Temperature affects the growth rate of microgreens. Since temperature was not used as an independent variable in this investigation, it was kept constant in all treatments, at approximately $20^{\circ} \mathrm{C}$.

\section{Other materials:}

The size of the plastic tray used in this study was $26.6 \times 20.9$ $\mathrm{x} 6 \mathrm{~cm}$. Water absorption will vary when different quantities of soil are used. Less water will be available for $V$. radiata germination if there is a greater depth of soil, as water will evenly diffuse throughout the soil. By keeping these factors in mind, $500 \mathrm{~g}$ soil was used for each treatment, and the depth was approximately $4 \mathrm{~cm}$. The soil contained a combination of humus, compost, and Canadian sphagnum peat moss. Fifty grams of $V$. radiata seeds were sowed for each treatment. The seeds were submerged in water for 24 hours before sowing. The hypocotyl length was measured using a measuring tape as mentioned in Figure 3.

\section{Acknowledgements}

The author would like to thank their biology teacher Ms. Carrie Warren for her continuous motivation and support throughout this project. Additionally, they would like to thank Dr. Adeyemi Adegbenjo, Research Associate, University of Guelph, for the help with the statistical analysis (two-way ANOVA).

\section{- References}

1. Mir, S.A.; Shah, M.A.; Mir, M.M. Microgreens: Production, Shelf Life, and Bioactive Compounds. Crit. Rev. Food Sci. 2017, 57, 2730-2736.

2. Choe, U.; Lucy, L.; Wang, T.T.Y. The Science Behind Microgreens as an Exciting New Food for the 21st Century. J. Agric. Food Chem. 2018, 66, 11519-11530.

3. Lambrides, C.J; Godwin, I.D. Mung bean. In Genome Mapping and Molecular Breeding in Plants: Pulses, Sugar and Tuber Crops, Springer Nature, Switzerland, 2007.

4. Samuoliene, G.; Virsile, A.; Brazaityte, A.; Jankauskiene, J.; Sakalauskiene, S.; Vastakatie, V.; Novickovas, A.; Viskeliene, A.; Sasnauskas, A.; Duchovskis, P. Blue Light Dosage Affects Carotenoids and Tocopherols in Microgreens. Food Chem. 2017, 228, 50-56.

5. Xiao, Z.; Lester, G.E.; Luo, Y.; Xie, Z.; Yu, L.; Wang, Q. Effect of Light Exposure on Sensorial Quality, Concentrations of Bioactive Compounds and Antioxidant Capacity of Radish Microgreens During Low Temperature Storage.

Food Chem. 2014, 151, 472-479.

6. Xiao, Z.; Lester, G.E.; Park, E.; Saftner, R.A.; Luo, Y. Evaluation and Correlation of Sensory Attributes and Chemical Compositions of Emerging Fresh Produce: Microgreens. Postharvest Biol. Tec. 2015, 110, 140-148.

7. Vastakatie, V.; Virsile, A.; Brazaityte, A.; Samuoliene, G.; Jankauskiene, J.; Anovickovas; Duchovskis, P. Pulse Light Emitting Diodes for a Higher Phytochemical Level in Microgreens. J. Agric. Food Chem. 2017, 65, 6529-6534.

\section{Author}

Manickavasagan Shivaani is a Grade 12 student at the Guelph Collegiate Vocational Institute, Guelph in the International Baccalaureate (IB) program. This study was conducted as part of a Biology Internal Assessment (IA). 